\title{
Los trabajadores, sus organizaciones y la responsabilidad social empresarial en el Perú: retos y posibilidades
}

\author{
ENRIQUE FERNÁNDEZ-MALDONADO MUJICA*
}

- Cuál seguridad social — dijo don Hilario—. Eso es para los empleados fijos.

- ¿No fui chofer fijo? - preguntó Ambrosio-. ¿Qué fui entonces, don?

- Cómo ibas a ser chofer fijo si no tienes brevete profesional —le explicó don Hilario.

- Claro que tengo — dijo Ambrosio-. Qué es esto, si no.

- Ah, pero no me lo dijiste y no es mi culpa — repuso don Hilario-. Además, no te declaré para hacerte un favor. Cobrando por recibo y no por planilla te librarás de los descuentos.

- Pero si cada mes usted me descontaba algo — dijo Ambrosio—. iNo era para el seguro social?

- Era para la jubilación — dijo don Hilario—. Pero como dejaste la empresa, ya perdiste los derechos. La ley es así, complicadísima.

Mario Vargas Llosa, Conversación en La Catedral

SUMARIO: INTRODUCCIÓN.- I. LUCES Y SOMBRAS SOBRE LA RESPON-

SABILIDAD SOCIAL EMPRESARIAL.- II. LA RSE "AMPLIADA».- III. RELACIONES DE TRABAJO EN EL PERÚ: DEL FRACASO DEL DIÁLOGO SOCIAL HACIA LA TENTACIÓN AUTORITARIA.- IV. LA RSE EN EL ÁMBITO LABORAL: RETOS Y POSIBILIDADES.- V. A MANERA DE CONCLUSIÓN.

\section{INTRODUCCIÓN}

Este epígrafe, perteneciente a una de las mayores obras de la literatura peruana, describe irónica pero certeramente el que es, en mi opinión, uno de los rasgos más expresivos de nuestra realidad social contemporánea: la precariedad laboral. El contexto histórico de la cita se remonta a mediados del siglo pasado, cuando las aspiraciones sociales de la clase trabajadora eran reprimidas por el gobierno de Odría (1948-1956). Sin embargo, pese al tiempo transcurrido, el relato mantiene una exasperante vigencia. Basta revisar algunos expedientes laborales, o simplemente conversar con la gente en la calle, para suponer que el Ambrosio que protagoniza el diálogo representa a un sector mayoritario de la población, al margen de los sistemas de protección y seguridad social relacionados con el trabajo. 
De acuerdo con un reciente informe de la Organización del Trabajo (OIT), el 70\% de la fuerza laboral peruana trabaja en la informalidad, sin acceso a derechos laborales y sociales básicos ${ }^{1}$. Asimismo, los trabajadores peruanos reciben los salarios promedio más bajos de la región, mientras que las situaciones de riesgo ocupacional y de explotación laboral se encuentran entre las más altas. Estamos, ciertamente, ante una problemática compleja y heterogénea, cuya comprensión y análisis excede la extensión de este espacio.

En este breve ensayo nos centraremos en analizar una de las dimensiones principales que explican el contexto de precariedad laboral extendida en el país: la persistencia de conductas autoritarias en el ámbito de las relaciones laborales. Nuestra hipótesis es que, de persistir este patrón de relacionamiento entre los actores sociales vinculados al mundo del trabajo y la economía, las posibilidades de alcanzar prácticas y comportamientos «socialmente responsables» en el interior de las empresas serán remotas, cuando no imposibles.

\section{LUCESYSOMBRASSOBRELARESPONSABILIDAD SOCIAL EMPRESARIAL}

Este discurso o corriente empresarial comienza a discutirse con mayor fuerza durante las décadas de 1960 y 1970, expresión de los cambios sociales, políticos y culturales ocurridos en las principales ciudades del mundo. Sin embargo, recién en los años noventa la responsabilidad social empresarial (RSE) adquiere un tono audaz e innovador, que presenta a las empresas como agentes preocupados y solidarios con los problemas sociales y ambientales de sus respectivos países o entornos.

Este «clima de época» llegó al Perú a mediados de la década pasada. Fue introducido por organizaciones no gubernamentales y centros de investigación, y rápidamente adoptado como discurso político y social por sectores importantes de la clase empresarial peruana. Se formaron asociaciones mixtas que involucraban a empresas y a la sociedad civil en la discusión de experiencias y en la organización de eventos de difusión ${ }^{2}$. El impacto del nuevo discurso empresarial caló significativamente en las percepciones de la gente: según una encuesta del Instituto de Opinión Pública de la PUCP (2009), el 70\% de limeños considera que el empresario peruano está comprometido con el desarrollo del país ${ }^{3}$.

Sin embargo, una mirada crítica y acuciosa de lo realmente avanzando en el terreno nos puede llevar a encontrar — en el caso peruanoavances significativos pero profundamente conservadores y acotados a

1 Organización Internacional del Trabajo (OIT). Memoria anual 2009.

2 Entre las más importantes y emblemáticas de nuestro país se encuentra la Red de Responsabilidad Social Empresarial del Perú, fundada en 2003 por un grupo de ONG de desarrollo, empresas grandes y medianas, centros universitarios y especialistas, para impulsar la difusión y la promoción de la RSE en el medio.

3 IOP-PUCP. «Encuesta sobre percepciones y opiniones del mundo empresarial», año IV, octubre de 2009. 
esferas que no afectan la lógica dominante del modelo económico. Ni siquiera en sus versiones más avanzadas — como se discute en el sindicalismo europeo- la RSE aparece como un medio para transformar o superar las contradicciones sistémicas de un modelo de crecimiento con profundas limitaciones para reducir la brecha entre beneficiados y excluidos del sistema. Las lecturas más «radicales» en torno a la RSE aspiran a corregir algunos de los aspectos más polémicos y perversos del sistema económico internacional — por ejemplo, el empleo infantil-, sin llegar a cuestionar la lógica autodestructiva del sistema que derivó en la crisis global iniciada en 2007: la mayor desde el Crack del 29.

El poder de atracción y persuasión de este discurso - una empresa que no contamina y respeta los derechos de sus trabajadores y clientes: ino suena atractivo? - se ha convertido en un lugar común del discurso políticamente correcto en nuestras sociedades. En nuestra opinión, la fuerza de este discurso radica en la idea de que es posible un capitalismo «bueno» o «sano», al que hay que proteger y estimular, en contraposición a un capitalismo «salvaje» o insostenible, que explota a sus trabajadores, estafa a sus clientes y destruye el medio ambiente, sin considerar las implicancias de su accionar en el mediano y largo plazo.

Con todo, la RSE aparece hoy como el discurso legitimador de un sistema económico que ingresa en una profunda crisis de legitimidad. En este escenario, signado por una mayor conciencia social sobre los efectos adversos del modelo de producción capitalista, la RSE adquiere un rol medular en el accionar de las empresas cuyas prácticas productivas o comerciales son cuestionadas o están expuestas a la vigilancia social de diversos grupos de interés. En efecto: cada vez son más los mercados bursátiles, fondos de inversión, corporaciones y agentes de comercio internacional, organismos multilaterales, asociaciones de consumidores, cámaras de comercio y sindicatos, entre otros grupos de interés, que se muestran sensibles a los efectos sociales y ambientales de la actividad empresarial y comercial.

Lo que comenzó en los años setenta como incipientes y aislados procesos de vigilancia social a las empresas multinacionales vinculadas al comercio internacional ${ }^{4}$ se convirtió en apenas dos décadas en una corriente empresarial basada en un discurso persuasivo y articulado que promovía un modelo de gestión estratégica del impacto social y ambiental de la actividad productiva: el denominado RSE. Durante los años noventa, la RSE se convirtió en un espacio de confluencia para instituciones y actores públicos y privados en el ámbito local e internacional —desde las agencias de financiamiento internacional, pasando por las asociaciones de consumidores, los sindicatos y el propio Estado- en torno a un

4 Entre los años 1976 y 1979 se adoptaron múltiples declaraciones internacionales que apuntaban a establecer parámetros para el accionar de las empresas multinacionales. Entre los más importantes están las directrices de la OCDE para Empresas Multinacionales (1976) y la Declaración Tripartita de la OIT de 1977, relativa a empresas multinacionales y política social. 
discurso «políticamente correcto» que genera amplios consensos sociales 5 . Se llegó a argumentar, incluso, que el aumento de las situaciones de conflictividad social vinculadas con industrias extractivas —además de responder a la ausencia histórica del Estado en estas zonas, por lo demás alejadas - estaban relacionadas con la ausencia o con la mala implementación de las políticas de responsabilidad social de las empresas implicadas.

En el ámbito laboral, como en otros ámbitos, la RSE supone una serie de procedimientos y regulaciones que establecen que una empresa actúa «justa»y «responsablemente» con sus trabajadores. Pero antes de abordar lo que esto implica en concreto conviene comenzar con una aclaración: en el Perú, como en otros países y regiones, las condiciones de trabajo dependen - en gran medida, aunque no exclusivamentede la institucionalidad laboral que regula las relaciones sociales de producción. Esto es: del corpus legal que define las reglas de juego para las contraprestaciones laborales en el ámbito público o privado, tanto para las relaciones individuales como para las colectivas del trabajo.

En un inicio, la aceptación social de una institucionalidad laboral estaba vinculada con los usos culturales de una colectividad reflejados en la esfera del trabajo, esto es, por la existencia de acuerdos sociales previos a su «institucionalización», vinculados con la tradición y la costumbre. Con la modernidad, la legitimidad de una norma pasó a depender de los acuerdos legislativos alcanzados por actores políticos que representan los intereses sociales de una sociedad ante sus instancias deliberativas, o bien por la vía ejecutiva, pero con cierto respaldo social ${ }^{6}$. Así vista, la normatividad laboral adquiere legalidad, en función de su origen legislativo o gubernamental, y legitimidad, al ser consecuencia del debate y de la negociación de las fuerzas sociales en tensión, que ven representados sus intereses en el sistema político.

En este esquema, las posibilidades de inclusión social a través del trabajo están directamente relacionadas con las políticas laborales y sociales implementadas por los gobiernos en el marco del modelo de desarrollo que adopta y en el carácter de su vínculo con la economía global. Depende también del pacto social que acoge una sociedad, el cual refleja

5 Para las propias empresas resultó ser un «discurso» atractivo, rápidamente incorporado. En el caso de las grandes empresas, la implementación de políticas de responsabilidad social se convirtió en un requisito para acceder y mantener alianzas estratégicas con socios internacionales, acceder a determinados mercados, brindar servicios, garantizar la fidelidad de sus consumidores, mantener sus niveles de rentabilidad y sostenibilidad de sus organizaciones, etcétera. En el caso de las pequeñas y medianas empresas, los intentos por acercarse a la responsabilidad social aparecen como «filtro» y «estímulo» para formar parte de conglomerados productivos vinculados con los mercados internacionales, así como entablar relaciones productivas de fortalecimiento institucional con otros actores o grupos de interés locales e internacionales.

6 Este último escenario se registró en el Perú de los años noventa, durante el primer gobierno de Alberto Fujimori (1990-1995), cuando se llevó a cabo una reforma laboral que flexibilizaba las relaciones individuales (decreto legislativo 728) y eliminaba el rol tutor del Estado en las relaciones colectivas (ley 25593) de trabajo. Estas leyes fueron aprobadas como parte de un paquete legislativo que el Ejecutivo presentó al Congreso luego de que este le delegará facultades legislativas, y contaron con una aceptación social mayoritaria en un contexto de inestabilidad política y económica. 
la correlación de fuerzas entre sus distintos sectores. En dicho pacto, el carácter del modelo económico guarda estrecha relación con las regulaciones del trabajo, lo cual convierte al factor empleo en una variable de ajuste o de promoción del crecimiento económico?

La importancia del sistema legal que regula las condiciones de trabajo - para todo efecto práctico, predominante en las últimas décadas- ha sido contrapuesto a un discurso relativamente nuevo que se presenta como moderno y «alternativo», que apunta a legitimar y promover sistemas de autorregulación empresarial orientadas a promover entornos sociales, laborales y ambientales «sostenibles» para nuestras sociedades y para las generaciones futuras. Este discurso ha sido nombrado «responsabilidad social empresarial» (RSE) o «corporativa» (RSC).

\section{LA RSE «AMPLIADA»}

En los últimos años, se ha desarrollado una serie de instrumentos de medición y de aplicación de la responsabilidad social en el ámbito interno de la empresa. La implementación de estos instrumentos - comúnmente conocidos como códigos de conducta ${ }^{8}$ - comenzaron a ser adoptados fundamentalmente con dos fines: por un lado, como guías o modelos de gestión para las empresas que apuntan a mejorar sus estándares laborales internos y/o externos - incluidos los de sus proveedores-, y que se servían de estos como parámetros e indicadores de cumplimiento; por otro lado, como «certificaciones» del cumplimiento de estándares laborales, ambientales y sociales reconocidos internacionalmente y exigidos por los grupos de interés - consumidores, clientes, contratistas y organizaciones vinculadas a los derechos laborales y humanos, entre otras-que vigilan y presionan para que aquellos se hagan efectivos. Para muchas empresas, la incorporación de estos instrumentos —que promueven su propia «autorregulación» al margen del Estado y que adoptan como parte de sus sistemas operativos y de gestión social— los hace susceptibles de autodenominarse «socialmente responsables».

¿Y cuáles son estos estándares cuyo cumplimiento garantiza un comportamiento socialmente responsable? Esta pregunta forma parte de los debates actuales sobre el tema; sin embargo, existe cierto consenso en considerar —en el caso de la dimensión socio-laboral de la RSE, motivo de este ensayo- los derechos y principios fundamentales en el trabajo de la OIT $^{9}$, a los que se incorporan —en algunos códigos o instrumentos de

7 Esto dependerá de si el sistema normativo laboral apunta a garantizar la tasa de ganancia empresarial como mecanismo para promover la inversión (modelo neoliberal) o bien favorece un proceso de crecimiento económico basado en el fortalecimiento del mercado interno, con lo cual incrementarían las posibilidades de participación económica de las clases laborales en él (modelo keynesiano).

8 Sobre el debate en torno a los códigos de conducta y sus implicancias para la RSE, véase CAMPANA, David y Javier MuJICA. Códigos de conducta y normas sobre responsabilidad social empresarial. Un desafío para la competitividad en la economía global. Lima: CEDAL, 1999.

9 La OIT reconoce cuatro principios y derechos fundamentales en el trabajo: la libertad de asociación o sindical (convenios 87 y 98); la abolición del trabajo infantil y sus peores formas; la eliminación del trabajo forzoso; y la igualdad de trato y no discriminación en el empleo (convenios 100 y 111).

LOS TRABAJADORES, SUS ORGANIZACIONES Y LA RESPONSABILIDAD SOCIAL EMPRESARIAL EN EL PERÚ: RETOS Y POSIBILIDADES 
responsabilidad social — otros aspectos vinculados al concepto de «trabajo decente ${ }^{10}$ (salario justo, jornada laboral y seguridad ocupacional). En esa línea, algunos de los más importantes instrumentos de RSE para el ámbito laboral — por ejemplo, la Norma SA 8000— basan su legitimidad y su credibilidad en las normas internacionales en materia de derechos humanos, incluidos los derechos fundamentales en el trabajo. Así, las empresas que adoptan estos instrumentos de «autorregulación empresarial» se comprometen a respetar ciertas dimensiones del Derecho internacional relacionado con los derechos humanos, aun cuando estas establezcan estándares más altos que los fijados por la regulación local o nacional — supuesto piso mínimo que algunos proponen para hablar de RSE-.

En lo que sigue, queremos proponer una forma de clasificación de las políticas y estrategias de RSE de acuerdo a los siguientes criterios: i. los estándares adoptados como parámetros de responsabilidad social; y ii. los niveles de implicación de la dirección con otros sectores dentro de la organización empresarial y con diversos grupos de interés.

Desde esta perspectiva, la RSE adquirirá mayor o menor legitimidad en la medida en que mantenga una convocatoria amplia basada en el involucramiento horizontal de la empresa con otros actores sociales, para la implementación y el monitoreo de las políticas de responsabilidad social adoptadas en sus respectivos centros de trabajo o cadenas productivas. Esta mayor implicación social de los grupos de interés tendrá mayor legitimidad si las políticas implementadas, además de nutrirse de una pluralidad de perspectivas y compromiso de los actores involucrados, se proyecta a cumplir con los estándares internacionales en materia de derechos humanos.

Esta forma de clasificar las políticas de RSE adquiere una naturaleza particular en el ámbito del trabajo. En los últimos años, se ha construido un consenso —que involucra a actores empresariales y laborales, además de instituciones especializadas- que enfatiza la necesidad de incorporar, de manera más rotunda, los principios y derechos fundamentales en el trabajo propuestos por la OIT, en el entendido de que ofrecen instancias de seguimiento y justicia internacional con posibilidades de fijar sanciones comerciales a países y empresas infractoras. Sin entrar directamente al debate, asumimos acá que las normas internacionales suponen un mayor nivel de exigibilidad y consistencia en la definición del contenido y del espíritu de los derechos humanos en el trabajo, por lo que fijarían un estándar superior al establecido en las legislaciones laborales locales o nacionales.

10 El trabajo decente es un concepto impulsado por la OIT durante los años noventa, con el fin de establecer parámetros para la exigibilidad y el cumplimiento de condiciones adecuadas de empleo en el marco de los procesos de globalización y comercio internacional. Entre sus principales componentes se encuentran los derechos fundamentales en el trabajo; la implementación de políticas de empleo por parte de los poderes públicos; el establecimiento de un salario justo (o mínimo); las políticas de diálogo social entre los actores involucrados; y las medidas preventivas y correctivas de seguridad y salud ocupacionales. 
En el siguiente gráfico presentamos un esquema de cuatro cuadrantes que indican intensidades y orientaciones distintas en el ejercicio práctico de la responsabilidad social. Un primer eje de análisis está centrado en los estándares adoptados como metas u objetivos a cumplir en el marco de las políticas de RSE. Por ejemplo, en el ámbito de la responsabilidad social «interna», una empresa que circunscribe sus políticas de RSE al cumplimiento de los estándares laborales fijados por la normatividad local o nacional, y que no incorpora a sus trabajadores u otros grupos de interés en el diseño y seguimiento de sus políticas de responsabilidad, operaría bajo una visión «restrictiva» de RSE cuya legitimidad es endeble o poco sostenible.

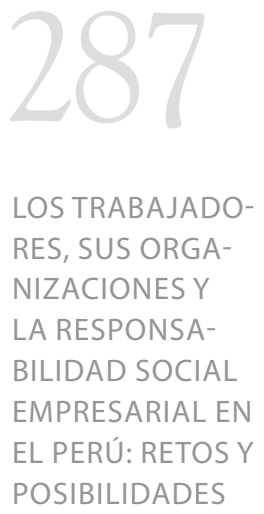

Gráfico 1.

Matriz para clasificar las políticas de responsabilidad social empresarial

\begin{tabular}{|c|c|c|}
\hline & & Ampliada \\
\hline & $\begin{array}{c}\text { Poca o nula } \\
\text { participación de grupos } \\
\text { de interés y estándares } \\
\text { internacionales }\end{array}$ & $\begin{array}{c}\text { Amplia } \\
\text { participación de } \\
\text { grupos de interés y } \\
\text { estándares } \\
\text { internacionales }\end{array}$ \\
\hline Restrictiva & $\begin{array}{c}\text { Poca o nula } \\
\text { participación de } \\
\text { grupos de interés y } \\
\text { estándares locales }\end{array}$ & $\begin{array}{c}\text { Poca o nula } \\
\text { participación de } \\
\text { grupos de interés y } \\
\text { estándares } \\
\text { internacionales }\end{array}$ \\
\hline
\end{tabular}

Fuente: Elaboración del autor.

Por el contrario, una política de responsabilidad social laboral «ampliada» es aquella que —además de conciliar las políticas laborales internas con los estándares internacionales en materia de derechos humanos laborales- supone la implementación de políticas de diálogo social con el personal de la empresa y sus organizaciones, así como la incorporación de otros actores o grupos de interés en el seguimiento y el monitoreo de los compromisos adoptados. Como precondición, los actores implicados — capital y trabajo— deben reconocerse como interlocutores válidos en condiciones de discutir - no solo— los puntos habituales de controversia y negociación (salarios, condiciones de trabajo, etcétera), sino que también participar en los procesos de diseño, aplicación y seguimiento de las políticas de responsabilidad social implementadas, incluido el monitoreo de los recursos financieros dispuestos para esos fines. 
Esta lectura o visión «ampliada» de la responsabilidad social se sostiene en un concepto de empresa como unidad productiva cuya estructura organizacional forma parte de un sistema complejo de relaciones en el que la eficiencia y compromiso de los actores depende —en el mediano y en el largo plazo- del respeto y del reconocimiento mutuo. La «complementariedad» estratégica que aparece implícita en la relación asalariada no desconoce el carácter central que ocupa el conflicto de intereses entre el capital y el trabajo en el sistema capitalista. Por el contrario, bajo este esquema la RSE se presenta como un espacio para la mediación de los conflictos sociales surgidos en el interior de la empresa, como paradigma de la «complementariedad estratégica» entre sus distintos componentes y actores. Desde esta perspectiva, las políticas de responsabilidad social que en lugar de ampliar la participación de los grupos de interés los excluyen o que se plantean parámetros de cumplimiento basados en los estándares sociales y ambientales más laxos resultarán a la larga insuficientes, ineficaces o simplemente inviables para promover y hacer viable la RSE: no solo por el impacto limitado de sus objetivos, sino principalmente por no sustentarse en consensos sociales básicos sobre el rol social de la empresa.

Resumiendo: una política de RSE con pretensiones de validez y legitimidad exigirá necesariamente el reconocimiento mutuo de los actores implicados en tanto agentes involucrados o afectados por una actividad empresarial o productiva. Pero sobre todo, exigirá de voluntad política y tolerancia - respecto de los intereses y demandas de sus contrapartescomo condición para negociar acuerdos que beneficien a todas las partes en proporciones razonables.

Desde esta perspectiva, el «éxito» de una política de RSE en el ámbito laboral se expresará - fundamentalmente- en la forma en que se adopten las relaciones sociales en el ámbito productivo. Esto es: las consecuencias concretas derivadas de las relaciones laborales en la calidad del empleo y la distribución social del ingreso, así como la existencia y eficacia de los canales de comunicación - formales e informales - establecidos por la empresa para canalizar los conflictos de interés y garantizar el normal funcionamiento del ciclo productivo. En lo que sigue, abordaremos estas dimensiones a partir de la siguiente pregunta: itiene futuro la responsabilidad empresarial laboral en el Perú?

\section{RELACIONES DE TRABAJO EN EL PERÚ: DEL FRACASO DEL DIALOGO SOCIAL HACIA LA TENTACIÓN AUTORITARIA}

Salvo situaciones excepcionales, en el Perú las relaciones de trabajo se han caracterizado por mantener una estructura desigual en la distribución del poder. Esta relación asimétrica se expresa a través de múltiples formas y mecanismos: aparece en la alta concentración del 
ingreso en los sectores capitalistas, en desmedro del ingreso laboral a pesar del contexto de crecimiento económico. Se encuentra también en la amplia discrecionalidad que ofrece la legislación laboral a las empresas para contratar y despedir personal, y que condena a un amplio sector de la población a laborar en «empleos precarios permanentes» ${ }^{11}$. También se expresa en la violación sistemática y abusiva de los derechos civiles y sociales de los trabajadores peruanos, en un contexto de impunidad y precariedad institucional extendida, como el descrito en la cita de Vargas Llosa.

Es en este escenario que resulta importante analizar la viabilidad de la RSE en el ámbito interno. Nuestra hipótesis es que la persistencia de rasgos autoritarios en las relaciones de trabajo no solo ha erosionado los niveles de confianza y legitimidad entre los actores sociales implicados - principalmente entre los gremios empresariales y sindicales-, sino que ha implicado también, por parte de los trabajadores, un claro recelo en torno al reciente interés social de las empresas. En algunos casos se han llegado a negar las posibilidades u oportunidades que supone un escenario de RSE «ampliada» en la concreción efectiva de —algunos de- sus intereses individuales y colectivos como trabajadores.

En el Perú, el ejemplo más ilustrativo del distanciamiento entre empresarios y trabajadores radica en el pobre desempeño del Consejo Nacional del Trabajo (CNT) como espacio de dialogo y concertación social. El CNT fue instituido como parte del Acuerdo Nacional alcanzado por las fuerzas políticas y sociales en el contexto de la transición democrática iniciada en 2001. Este foro, que funciona como parte de la institucionalidad del Ministerio de Trabajo y Promoción del Empleo (MTPE), convocó a los principales gremios empresariales y sindicales para que, con el apoyo de «técnicos» y agencias especializadas, diseñaran, negociaran y acordaran un nuevo marco normativo que modernizara y organizara el cuerpo legal existente, al incorporar una serie de observaciones realizadas por la OIT a la legislación laboral heredada del fujimorismo. Este nuevo marco sería la nueva Ley General del Trabajo (LGT).

Sin embargo, tras casi diez años de discusiones y negociaciones, los actores involucrados no lograron consensuar el conjunto de aspectos considerados en los diversos proyectos de ley que se discutieron. Ello impidió la aprobación de un «nuevo pacto laboral» que conciliara ciertos niveles de flexibilidad laboral, con una mayor protección social para los trabajadores; asimismo, afectó la credibilidad y la legitimidad del CNT como espacio de diálogo social y negociación laboral. Hasta hoy ${ }^{12}$.

11 CAmpodónICO, Humberto. «El empleo precario permanente». La República, primero de marzo de 2010.

12 Una lectura distinta a la que presento acá sobre el desempeño del CNT se puede ver en GAMARRA, Leopoldo. «La Ley General de Trabajo: experiencia de diálogo social». Coyuntura, № 14, año 3, septiembre-octubre de 2007. 
Esta imposibilidad para lograr acuerdos sociales estables se ha reflejado, en el ámbito del trabajo, en la sucesión de situaciones de conflictividad laboral que alcanzaron niveles extremos en sectores como la minería, la industria manufacturera o los puertos, por mencionar algunos casos. Así se pusieron en evidencia las limitaciones de un marco institucional que obstaculiza los canales de diálogo social y de negociación colectiva, y que agudiza las tensiones sociales entre empresarios y trabajadores, en un período en el que las ganancias de los primeros aumentaban y la de los segundos no. En este escenario, la persistencia de patrones autoritarios en la relación entre empleadores y trabajadores - lo que es peor: amparados por el Estado— representa el principal obstáculo para impulsar políticas de RSE de carácter «ampliado» en el ámbito interno o laboral.

\section{LA RSE EN EL ÁMBITO LABORAL: RETOS Y POSIBILIDADES}

Reflexionando sobre el caso peruano, nos preguntamos por las posibilidades que se abren a futuro para un real involucramiento de los actores empresariales y laborales en la formulación de políticas laborales y sociales que apunten a un desarrollo social sostenido y compartido. Más específicamente: iestán estos actores en condiciones de iniciar procesos de diálogo social orientados al diseño, la implementación y el monitoreo de políticas de RSE en el ámbito interno - y externo- de las empresas?

A partir de los antecedentes señalados, las posibilidades de extender la responsabilidad social hacia el ámbito laboral aparecen distantes, por lo menos en el corto plazo. Pese a que en los últimos años asistimos a un número importante eventos —académicos, corporativos, mediáticos, publicitarios y hasta sindicales - en torno a las oportunidades, potencialidades y límites de la responsabilidad social como corriente de pensamiento y práctica empresarial, lo concreto es que los avances registrados hasta la fecha son pocos, muchas veces confundidos con acciones de filantropía empresarial y con bajos niveles de participación social ${ }^{13}$. Así visto, el promedio de acciones de RSE en el ámbito interno en el Perú se caracteriza por su carácter restrictivo, lo que supone poca participación de los trabajadores y estándares laborales fijados en función de lo que establece la normatividad laboral vigente.

En el ámbito laboral, para que una política de responsabilidad social adquiera legitimidad y se torne efectiva en el sentido amplio, resulta necesario que se plantee como objetivo reducir la desigual distribución del poder en las relaciones laborales - lo que implica, para el caso peruano,

13 Un acercamiento a las políticas de responsabilidad social empresarial en el ámbito laboral se puede encontrar en BEDOYA, Carlos Alonso y Enrique FERnÁndEZ-MALDONADO MuJICA. Derechos laborales y responsabilidad social empresarial. Cinco estudios de caso. Lima: CEDAL, 2004. Para el caso de la responsabilidad social en las mypes, véase FERNÁNDEZ-MALDONADO, Enrique y Luis GálveZ. Pequeños negocios, grandes responsabilidades. Estudio sobre la responsabilidad social de las mypes en Lima Metropolitana. Lima: Red Puentes, 2008. 
la aprobación de un nuevo marco institucional acorde con las condiciones actuales de los mercados laborales y los requerimientos de protección social de los trabajadores-. En el Perú, el ejercicio asimétrico del poder en el trabajo adquirió características alarmantes, lo que se reflejó en una abrupta reducción de la tasa de afiliación sindical, que pasó de representar en 1981 el 58\% de la PEA sindicalizable a tan solo el 13\% en 1997 y el 9\% en 2000.

Este hecho específico —e ilustrativo, por cierto, de la situación de repliegue y debilidad política del movimiento sindical peruano- requiere ubicarse en el contexto de dominación cultural impuesto por el proyecto neoliberal a nivel global, donde la inversión privada es presentada como pilar del desarrollo económico, mientras que el sindicalismo se circunscribe - en el mejor de los casos- a funciones estrictamente reivindicativas o laborales. En los últimos años, este esquema ha sufrido cambios: se ha incorporado una imagen abusiva y nociva - y en muchos casos, justificada - del actor empresarial, lo que ha generado cierto clima de escepticismo e insatisfacción en algunos sectores sociales ${ }^{14}$.

$\mathrm{Si}$ a la persistencia de prejuicios y estereotipos en los vértices de la mesa laboral se suma la ineficacia del Estado, el clima de confianza necesario para impulsar procesos de diálogo social, para prevenir conflictos laborales y para negociar acuerdos sostenibles y aceptados por todas las partes aparece con una condición difícil del alcanzar, por lo menos en el corto plazo. En lo que sigue, presentamos los hallazgos obtenidos en una serie de investigaciones recientes que nos parece importante citar en la medida en que refuerzan nuestras hipótesis sobre la viabilidad de la responsabilidad social empresarial laboral en el Perú.

\section{IV.1. Sobre la libertad sindical}

Un aspecto crucial en las posibilidades de implementar políticas de responsabilidad social en el ámbito interno está relacionado con el carácter que se le asigna al interlocutor empresarial y sindical en una relación específica — por ejemplo, en el CNT—, así como los aspectos considerados «tratables» en un proceso de negociación colectiva y de diálogo social. En este punto, resulta clave la percepción que tienen las partes respecto de la libertad de asociación o sindicalización y respecto de su importancia para la implementación de políticas laborales concertadamente, incluidas las de responsabilidad social empresarial.

Una investigación reciente de Julio Gamero nos ofrece pistas interesantes para acercarnos a la percepción empresarial sobre el empleo y

14 De acuerdo la encuesta sobre empresas publicada por IOP-PUCP, 37\% de los encuestados considera que los empresarios son explotadores y abusivos, $31 \%$ que no se preocupan por los trabajadores, $14 \%$ que son autoritarios, $13 \%$ que son egoístas, $11 \%$ que son conformistas que no arriesgan y $7 \%$ que no respetan los derechos de los trabajadores (véase el gráfico 2).

LOS TRABAJADORES, SUS ORGANIZACIONES Y LA RESPONSABILIDAD SOCIAL EMPRESARIAL EN EL PERÚ: RETOS Y POSIBILIDADES 


\section{Gráfico 2}

Principales características atribuidas a los empresarios en Lima Metropolitana (en porcentajes)

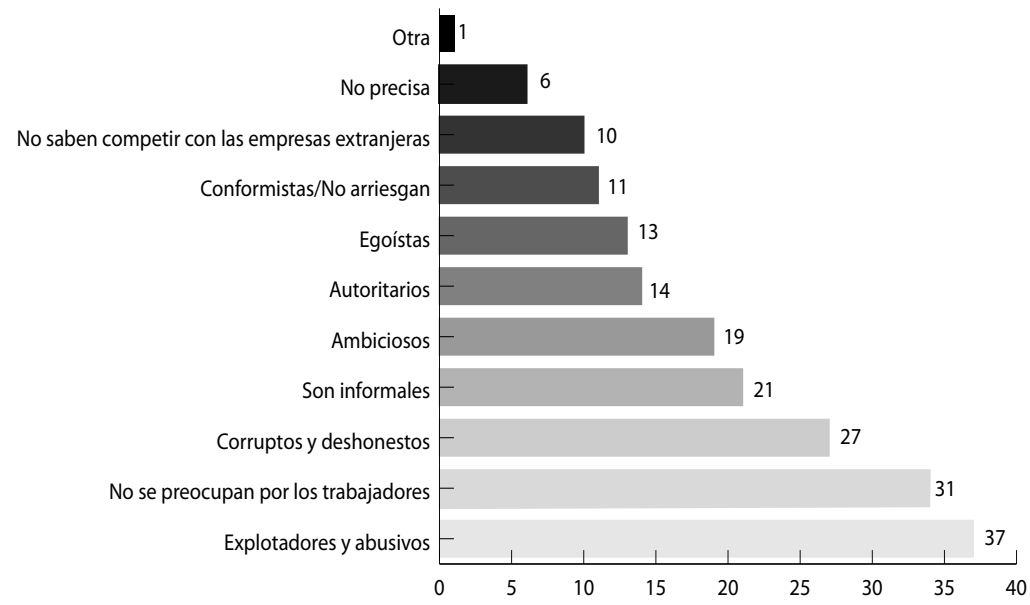

Fuente: Elaboración propia sobre la «Encuesta sobre empresas» de IOP-PUCP (2009).

las relaciones de trabajo ${ }^{15}$. Según esta investigación, en la que se entrevistó a 309 empresarios de Lima Metropolitana, el 91\% de empresas encuestadas manifestó no contar ni negociar con sindicatos. De este total, 63,8\% lo atribuyó al desinterés de los propios trabajadores - lo cual resulta posible, considerando el poco apego que existe en el medio hacia los sindicatos-, mientras que un 38\% manifestó «no necesitarlos» o que pueden «generar conflicto». Sin embargo, 51,9\% de los empresarios consultados afirmó que los sindicatos contribuyen a mejorar el clima de cooperación en el interior de la empresa - $63 \%$ en el caso de la mediana empresa-, mientras que 40,7\% reconoció que pueden mejorar la productividad — $56 \%$ en el caso de la gran empresa-.

Así vistas, las respuestas obtenidas entablan contradicción con las tasas efectivas de sindicalización y de negociación colectiva registradas en el medio — en Lima Metropolitana, la sindicalización es apenas del 4,8\% de la PEA sindicalizable-. iCómo entender, si no, que la mitad de las empresas encuestadas asocie a los sindicatos con mejoras en la productividad y el clima interno de la empresa, pero que en la práctica el ejercicio de la sindicalización en el Perú encuentre múltiples dificultades y obstáculos? 
Esta tensión se percibe incluso en los sectores «modernos» y rentables de la economía peruana, supuestamente abiertos a las nuevas corrientes de la gestión empresarial. Un informe reciente sobre las políticas de responsabilidad social en un conjunto de empresas multinacionales que lideran el ranking de empresas con mayor rentabilidad en el medio encuentra que «los derechos laborales más vulnerados son la libertad sindical y la negociación colectiva, básicamente en empresas de intermediación laboral en las que las posibilidades para la organización de los trabajadores y su defensa son mucho más reducidas ${ }^{16}$, lo que va en contra del espíritu «cooperativo» que se le asigna a los sindicatos en la encuesta.

El estudio citado indica que durante los últimos cinco años - período en el que la economía creció a un promedio anual de 8,9\%- solo el 2,9\% de empresarios reconoció enfrentar intentos de sindicalización en sus empresas - un $1.8 \%$ indicó que actuaron como meros espectadores y un $1,1 \%$ que buscaron convencer para se desista de dicha iniciativa-. Consultados ante el eventual intento de sindicalización en sus organizaciones, el 47,4\% y 6,2\% de los encuestados, respectivamente, indicó que «solo observarían dicho proceso» o que «los apoyaría»; pero un $36,1 \%$ - poco más de un tercio de las empresas encuestadas - tratarían de «hacer desistir a los trabajadores de dicha idea».

Este último porcentaje coincide con el 38\% de encuestados que considera a los sindicatos «innecesarios», prescindibles, lo cual revelaría —en términos de Gamero- «una valoración ambigua [...] con las repuestas que enfatizan en el aporte de los sindicatos en la productividad y clima de cooperación en la empresa». Gamero deja entrever que esta situación provocaría que «procesos futuros de sindicalización pueden generar resistencias como las que se ha venido observando en las nuevas empresas surgidas durante el pasado ciclo expansivo».

Por otro lado, el estudio en cuestión revela que la mayoría de las empresas encuestadas vinculan la actividad sindical con la negociación colectiva y con la solución de controversias entre trabajadores y empresas $(70,4 \%)$. El alto porcentaje de respuestas pone en evidencia un claro sesgo empresarial respecto del rol de los sindicatos, marginados para todo efecto práctico de los procesos vinculados a la competitividad y productividad de la empresa — como el diseño organizacional y operativo de las innovaciones tecnológicas y del trabajo interno-. Esta imagen particular que pesa sobre los sindicatos peruanos impide que se los considere una vía de interlocución legítima y necesaria entre

16 PLADES. «Informe 2007: las empresas transnacionales y los derechos laborales en el Perú». En este estudio, PLADES realiza un seguimiento de las políticas de responsabilidad social laboral en 28 empresas multinacionales. Entre sus conclusiones, encuentra que «Si bien el nivel de sindicalización se ha incrementado en la mayoría de las empresas estudiadas, las prácticas antisindicales también han ido en aumento, sobre todo con aquellos sindicatos recientemente organizados o en proceso de constitución. Los nuevos sindicatos se enfrentan a un conjunto de hostilizaciones que dificultan seriamente sus posibilidades de consolidación y desarrollo, lo que pone en evidencia la resistencia de reconocer a los sindicatos como actores clave en las relaciones laborales". En <http://www. plades.org.pe/publicaciones/informes-empresas2008.html>.

LOS TRABAJADORES, SUS ORGANIZACIONES Y LA RESPONSABILIDAD SOCIAL EMPRESARIAL EN EL PERÚ: RETOS Y POSIBILIDADES 
la empresa y los trabajadores, aspectos indispensables para buscar una mayor implicación de estos con los objetivos de la empresa ${ }^{17}$.

\section{IV.2. Percepción sobre las relaciones laborales}

La viabilidad futura de la responsabilidad social en el ámbito laboral está relacionada con la percepción de los actores sociales sobre el funcionamiento del sistema de relaciones laborales. En un escenario de funcionamiento «normal» del sistema de relaciones laborales — entendido este como la relación entre empresarios y trabajadores en el marco de un sistema normativo específico-, las posibilidades de lograr consensos en torno al rol social de las empresas se ven incrementadas al mejorar tanto el rendimiento político e institucional de los actores sociales como la calidad institucional en la administración de justicia, incluidos los procedimientos vinculados a la prevención y solución de conflictos. Ciertamente, el apego a la legalidad e institucionalidad laboral representan el primer paso hacia la responsabilidad social laboral, pero no agotan el repertorio de posibilidades y oportunidades que abre su práctica en el sentido amplio sugerido.

Sobre este tema, el estudio en cuestión encuentra una ligera mayoría de empresas $(53,4 \%)$ que considera que el sistema de relaciones laborales funciona bien; mientras tanto, que un $74 \%$ calificaba de «armoniosa» su relación con el sindicato. Al margen del carácter polémico de estos hallazgos (Gamero se pregunta si, dada la baja presencia de sindicatos en el país, existiría cierta tendencia en el empresariado a desconocer a la organización sindical como parte integrante de dicho sistema), es importante reparar en los tres factores que el $46,6 \%$ restante de encuestados considera necesarios para mejorar las relaciones laborales en el país: i. cambios en la regulación de la negociación colectiva; ii. cambios en el sindicalismo; y iii. modificación de las leyes laborales.

En lo que respecta a la negociación colectiva, es indudable que esta representa una institución laboral en crisis. El origen de esta crisis responde a múltiples factores: desde las reformas laborales implementadas por el fujimorismo en los años noventa, incluidos los despidos por privatización, hasta la violencia política contra dirigentes sindicales, además de los problemas de representatividad y legitimidad de las propias organizaciones sindicales. En los últimos años, aun cuando se registró un -moderado- aumento en el número de sindicatos nuevos y en la tasa de afiliación sindical, las negociaciones colectivas crecieron en una proporción menor al número de sindicatos creados (véanse los cuadros 3 y 4). Esta situación estaría revelando una enorme dificultad por parte de

17 «Las respuestas mayoritarias en relación con eventuales temas a negociar con el sindicalismo son elocuentes [...]. En ningún nivel de actuación se le reconoce como interlocutor. Ello no sólo estaría reflejando el bajo índice de sindicalización actual». En GAMERO, Julio. «Resultados preliminares de una encuesta de empresas». L. cit. 
los trabajadores para negociar un pacto colectivo con sus empleadores, pese al escenario económico favorable de los últimos años ${ }^{18}$.

Por otro lado, están los que consideran que «la reforma legal [o] constitucional representa la principal vía para producir cambios en las relaciones laborales». En la medida en que la encuesta está dirigida a empresarios, el autor considera que esta lectura no expresaría necesariamente los intereses de los actores sociales involucrados en una relación de trabajo (empresarios y trabajadores), sino, más bien, los de la clase política ${ }^{19}$.

Finalmente, hay quienes se inclinan por «privilegiar la negociación bilateral y el diálogo tripartito [...] y una mayor participación de los representantes de las partes involucradas». Esta opinión nos parece especialmente relevante en la medida en que la responsabilidad social en el ámbito laboral supone, para garantizar su legitimidad y viabilidad, la existencia de interlocutores reconocidos y aceptados por las partes en conflicto -interlocutores laborales, principalmente, ya sea a través de sindicatos u otros tipos de organización autónoma de los trabajadores, la parte más débil en una relación labora ${ }^{20}$ -

En ese sentido, merece destacarse la ausencia de mecanismos de representación informal entre las empresas encuestadas: 78\% manifestó que ni los trabajadores más antiguos o líderes naturales hacen las veces de interlocución y representación ante la empresa. La comunicación entre esta y su personal se registra a través de reuniones grupales $(50,4 \%)$, comunicados o asambleas convocadas de manera unilateral, mecanismos que, como plantea Gamero, representan espacios de información pero no de negociación o exposición de intereses, como sí ocurre en el ámbito de la negociación colectiva.

En síntesis, el estudio sugiere la aparición de dos tendencias medianamente claras sobre cómo mejorar, en el futuro, las relaciones laborales en el Perú. Por un lado, están quienes consideran la reforma legal o

18 «La negativa del empleador a aceptar la existencia del sindicato, la carencia de facilidades para las actividades sindicales, la falta de licencia, la negativa de las empresas al descuento sindical y a brindar información para la negociación colectiva como los incentivos económicos a los no sindicalizados, actos de hostilidad, despidos, etc. así como la falta de mecanismos de protección y las trabas que se ejercen desde el Estado, a través del MTPE, impiden el ejercicio efectivo de la libre sindicalización y negociación colectiva». En CASTELLANOS, Paúl. «Las trabas a la negociación colectiva». Trabajo y Desarrollo, $\mathrm{N}^{\circ}$ 3. marzo de 2008. Gamero se pregunta al respecto «si la negociación colectiva tiene un nivel bajo de cobertura, dado el bajo índice de la sindicalización, y a ella se le señala como objeto de un cambio para que el sistema de relaciones laborales funcione bien, ¿qué se estaría esperando de ella?».

19 Esta última afirmación merecería mayor discusión. En principio, porque la ausencia de una nueva norma general que regule las relaciones de trabajo tiene como principal responsable, precisamente, a la clase política en el Congreso, incapaz de aprobar el proyecto de ley tras casi diez de discusión. Por otro lado, de acuerdo con encuestas recientes realizadas por IOP-PUCP (Empresas, octubre de 2009, Lima Metropolitana), entre las principales tareas exigidas al Gobierno para promover la actividad empresarial aparece, en segundo lugar, el restablecimiento de la estabilidad laboral (16\%), después de la innovación tecnológica $(26 \%$ ) y, casi a la par de las facilidades para la exportación de recursos naturales (15\%), la reducción de impuestos (14\%) y el acceso al crédito (14\%).

20 En cuanto a las leyes laborales, Gamero encuentra que «la regulación de la contratación y del despido [...] son calificados como aspectos inflexibles de la legislación laboral $(73,2 \%)$. Sin embargo, aparecerían bajo un mismo calificativo dos temas muy distintos».

LOS TRABAJADORES, SUS ORGANIZACIONES Y LA RESPONSABILIDAD SOCIAL EMPRESARIAL EN EL PERÚ: RETOS Y POSIBILIDADES 


\section{Gráfico 3}

Evolución de proporción de trabajadores sindicalizados a nivel nacional

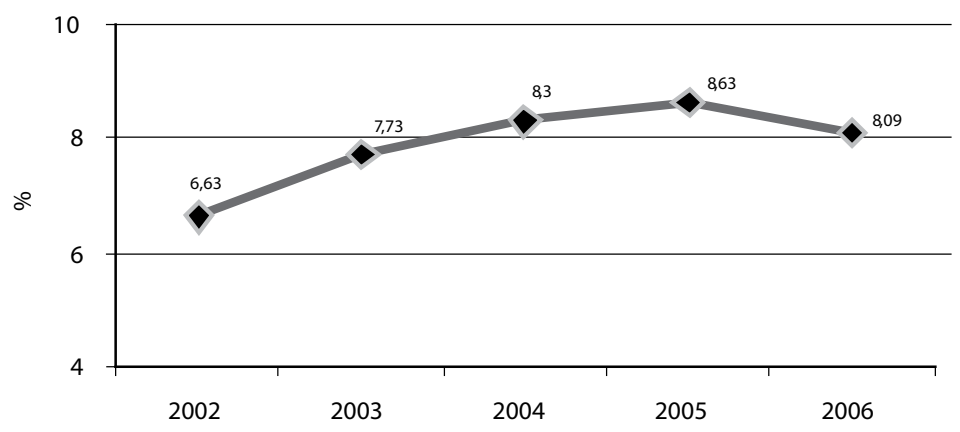

\% total de trabajadores sindicalizados

Gráfico 4

Convenios colectivos registrados a nivel nacional*

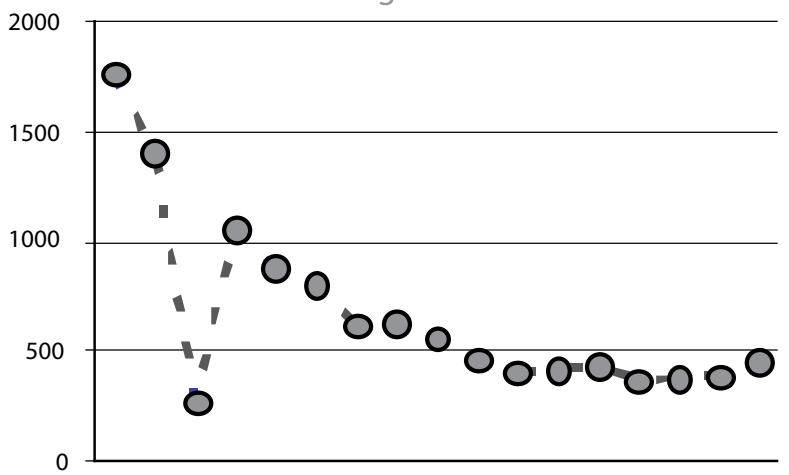

$90 \quad 9192 * * 93 \quad 9495 \quad 9697 \quad 98 \quad 9900 \quad 01 \quad 02 \quad 03 \quad 04 \quad 05 \quad 06$

* Incluye Pliegos de reclamos presentados en años anteriores y solucionados a la fecha.

** La información de 1992 corresponde a Lima Metropolitana.

Fuente: Oficina de Estadística e Informática - MTPE.

Información de las Hojas de Resumen de Planillas.

constitucional — por ejemplo, mediante la aprobación de la Ley General del Trabajo- como vía principal para forzar una reforma general del sistema de relaciones laborales. En esta línea se enmarcan los principales gremios sindicales —CGTP y CUT—, así como organizaciones de la sociedad civil. Asimismo, están quienes enfatizan la negociación directa entre actores como el medio idóneo para forzar un cambio en el sistema de relaciones laborales ${ }^{21}$.

21 Este aspecto es especialmente sensible. Uno de los aspectos más cuestionados de la ley 25593 promulgada por Fujimori es que privilegia la negociación a nivel de empresa, en desmedro de la negociación colectiva por rama de actividad. Esta situación perjudica a determinados sectores que, por determinadas características (predominio de contratos temporales, tercerización y transnacionalización), deben avanzar hacia un nivel superior de negociación. Pese a las modificaciones durante el gobierno de Toledo, la negociación colectiva y la huelga son derechos con amplios obstáculos para ejercerse en el Perú. 
Entre ambos planos se ubica el debate sobre la RSE en el ámbito laboral: es decir, en el apego a las instituciones tradicionales del Estado de Derecho - por ejemplo, la negociación colectiva-, entendidas como principios reguladores de las relaciones laborales, o en un escenario alternativo - creemos que no necesariamente excluyente, sino, por el contrario, complementario-, basado en la incorporación de mecanismos de autorregulación empresarial como instrumentos ordenadores de las relaciones sociales en el ámbito de la producción, siempre que se apliquen en el marco de una política de RSE ampliada.

\section{A MANERA DE CONCLUSIÓN}

Entendemos la RSE como una corriente empresarial que surge como consecuencia de la agudización de la crisis de productividad —y legitimidad - que experimenta el sistema capitalista desde las décadas de 1960 y 1970 del siglo pasado, y que ha llevado al capitalismo a replantear su relación con el Estado y con la sociedad, de cara a mantener su primacía como sistema económico y cultural hegemónico a nivel global. El análisis de la responsabilidad social — su importancia, sus implicancias reales y los objetivos subalternos que persigue - debe realizarse en este contexto amplio, signado por los cambios estructurales ocurridos en el último cuarto de siglo, especialmente en las sucesivas crisis financieras de la última década y media —la del tequila (1995), la del sudeste asiático (1997), la rusa y brasilera (1998), la argentina (2001-2002) y más recientemente la crisis financiera global iniciada en 2007-que pusieron en el centro de la agenda global la viabilidad del modelo neoliberal y, específicamente, el rol social de la empresa capitalista como motor del desarrollo.

Asimismo, resulta difícil imaginar la RSE sin la acción concertada de actores sociales y de movimientos ciudadanos interconectados a través de redes globales de vigilancia social, dedicadas a fiscalizar el impacto económico, laboral y ambiental de empresas e industrias calificadas como «riesgosas». Es en este contexto que la responsabilidad social adquiere relevancia política y social para las empresas. La sucesión de denuncias y campañas en contra de empresas que afectan el medio ambiente, que explotan a sus trabajadores o que están vinculadas a casos de corrupción ha movilizado un conjunto de voluntades que, individualmente a través de la adopción una ética del consumo «responsable», o colectivamente mediante su participación en organizaciones y redes de presión y vigilancia ciudadana, vienen incidiendo en los niveles de competitividad, credibilidad y rentabilidad de las empresas, y que las obligan a tomar cartas en el asunto.

Ciertamente, los casos de vigilancia social —impulsados desde la sociedad civil— considerados «exitosos» resultan a todas luces insuficientes para modificar las condiciones estructurales que se aspira transformar, 
pero abren un derrotero. Así, estos pocos casos registrados posibilitan — -según el concepto de Tarrow (1998) — la existencia de «estructuras de oportunidad», que pueden ser capitalizadas por distintos grupos de interés para forzar a empresas e industrias a adoptar políticas de responsabilidad social en sus procesos productivos ${ }^{22}$. La pregunta que intentamos responder en este breve ensayo gira en torno a la estructura de oportunidades que abre el discurso sobre la RSE para promover relaciones de trabajo justas y equitativas, que permitan mejorar la calidad de vida y de empleo de los peruanos.

Para que ello sea posible, creemos importante que tanto los gremios empresariales como los sectores laborales profundicen en la reflexión sobre lo que implica la RSE — sus límites, sus vacíos y sus contradicciones internas - como sistema de gestión empresarial: en particular, las potencialidades y oportunidades que abre para propiciar un cambio hacia un modelo de relaciones laborales más justo y equitativo. Finalmente, cabe preguntarnos si la RSE representa un medio para superar las contradicciones internas del modelo neoliberal: esa tensión entre capitalismo y democracia, entre acumulación privada y participación política, que nos ha llevado — en términos de Cotler - a «insalvables conflictos surgidos del carácter antagónico de los actores y la débil autonomía estatal para conciliar diferentes intereses, determinando la consecución de sucesivas crisis que han abarcado al conjunto del orden social en nuestro país» ${ }^{23}$.

22 Entre los más publicitados se halla el boicot comercial que sufrió la firma deportiva Nike, denunciada por emplear trabajo infantil durante plena campaña como sponsor oficial de la Copa Mundial de Fútbol Francia 98. Destapado el caso en medios, Nike se comprometió a respetar estándares internacionales en material laboral, monitoreados independientemente por organizaciones especializadas. Un ejemplo más reciente y destacado a nivel internacional radica en el conflicto intergubernamental que enfrenta a los gobiernos argentino y uruguayo desde 2003, originado por la instalación de industrias papeleras en la ribera oriental del río Uruguay, bajo riesgo de contaminación ambiental y paisajística. En esta oportunidad, mediante acción colectiva, grupos ecologistas, ambientalistas, juntas vecinales y agrupaciones políticas - atrincheradas en el publicitado "corte» del puente Gualeguaychúpresionaron y lograron contener la instalación de las plantas de celulosa, por lo menos hasta que se determine judicialmente su viabilidad y legalidad.

23 COTLER, Julio. "Capitalismo y democracia en el Perú: la tentación autoritaria». En Luis Pásara (editor). Perú en el siglo XXI. Lima: PUCP, 2008, p. 383. 